Braz J Med Biol Res, January 2011, Volume 44(1) 66-72

doi: 10.1590/S0100-879X2010007500147

Surfactant protein B gene polymorphism in preterm babies with respiratory distress syndrome

P.P.R. Lyra, E.M.A. Diniz, K. Abe-Sandes, A.L.D. Angelo, T.M.B. Machado and M. Cardeal

The Brazilian Journal of Medical and Biological Research is partially financed by

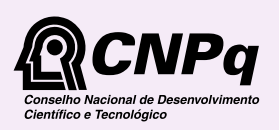

da Ciência e Tecnologia

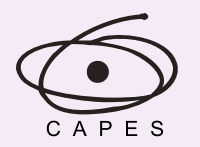

Ministério da Educação

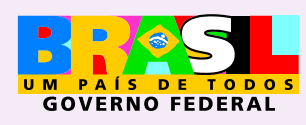

GOVERNO FEDERAL
DTFAPESP

Institutional Sponsors
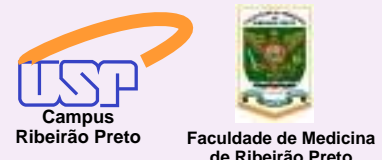

$\oplus$ SHIMADZU

GE Healthcare
Hotsite of proteomics metabolomics developped by: 


\title{
Surfactant protein B gene polymorphism in preterm babies with respiratory distress syndrome
}

\author{
P.P.R. Lyra ${ }^{1,2}$, E.M.A. Diniz ${ }^{1}$, K. Abe-Sandes ${ }^{5}$, A.L.D. Angelo ${ }^{3}$, \\ T.M.B. Machado ${ }^{3,6}$ and M. Cardeal ${ }^{4}$ \\ 1Departamento de Pediatria, Faculdade de Medicina, Universidade de São Paulo, São Paulo, SP, Brasil \\ ${ }^{2}$ Departamento de Pediatria, Faculdade de Medicina da Bahia, ${ }^{3}$ Programa de Pós-graduação em Imunologia, \\ Instituto de Ciências da Saúde, ${ }^{4}$ Centro de Pesquisa Fima Lifshitz, Universidade Federal da Bahia, Salvador, BA, Brasil \\ ${ }^{5}$ Departamento de Genética, Universidade Estadual da Bahia, Salvador, BA, Brasil \\ ${ }^{6}$ Laboratório Avançado de Saúde Pública, Centro de Pesquisas Gonçalo Moniz, FIOCRUZ, Salvador, BA, Brasil
}

\begin{abstract}
The etiology of respiratory distress syndrome (RDS) is multifactorial and multigenic. Studies have suggested that polymorphisms and mutations in the surfactant protein B (SP-B) gene are associated with the pathogenesis of RDS. The objectives of this study were to determine and compare the frequencies of SP-B gene polymorphisms in preterm babies with and without RDS. We studied 151 neonates: 79 preterm babies without RDS and 72 preterm newborns with RDS. The following four SP-B gene polymorphisms were analyzed: $\mathrm{A} / \mathrm{C}$ at $-18, \mathrm{C} / \mathrm{T}$ at $1580, \mathrm{~A} / \mathrm{G}$ at 9306 , and $\mathrm{G} / \mathrm{C}$ at nucleotide 8714 . The polymorphisms were detected by PCR amplification of genomic DNA and genotyping. The genotypes were determined using PCR-based converted restriction fragment length polymorphisms. The control group consisted of $42(53 \%)$ girls and $37(47 \%)$ boys. Weight ranged from 1170 to $3260 \mathrm{~g}$ and mean gestational age (GA) was 33.9 weeks (range: 29 to 35 weeks and 6 days). The RDS group consisted of $31(43 \%)$ girls and 41 (57\%) boys. Weight ranged from 614 to $2410 \mathrm{~g}$ and mean GA was 32 weeks (range: 26 to 35 weeks). The logistic regression model showed that GA was the variable that most contributed to the occurrence of RDS. The AG genotype of the A/G polymorphism at position 9306 of the SP-B gene was a protective factor in this population (OR $=0.1681 ; 95 \% \mathrm{Cl}=0.0426-0.6629)$. We did not detect differences in the frequencies of the other polymorphisms between the two groups of newborns.
\end{abstract}

Key words: Newborn respiratory distress syndrome; Genetic polymorphism; Surfactant protein B

\section{Introduction}

Pulmonary surfactant is a lipid-protein complex essential for normal lung function. It is responsible for decreasing the surface tension of the air-liquid interface of the alveoli, thus preventing lung collapse at the end of expiration (1).

The surfactant is a mixture of lipids ( $90 \%)$ and proteins $(\sim 10 \%)$ with phospholipids representing $80-90 \%$ of surfactant lipids. Phosphatidylcholine is the most prevalent, accounting for $70-80 \%$ of the total. Dipalmitoylphosphatidylcholine (DPPC) represents about $60 \%$ of the phospholipids and is the principal surface tension-lowering component of pulmonary surfactant (2). The following four proteins are associated with the surfactant complex: SP-A, SP-B, SP-C, and SP-D. They play important roles in surfactant function and metabolism (3).
In 1959, Avery and Mead (1) showed that pulmonary surfactant deficiency is a major factor in the pathophysiology of respiratory distress syndrome (RDS). The incapacity of the premature baby to produce surfactant in an appropriate quantity and the structural immaturity of the lung constitute the primary etiologies of RDS (1). The incidence of RDS increases with decreasing gestation period, with about $25 \%$ of babies affected at 34 weeks of gestation and up to $80 \%$ of babies affected at less than 28 weeks (4).

In spite of pulmonary surfactant replacement therapy and/or other therapies (maternal steroids treatment), RDS remains a cause of concern. The etiology of RDS is multifactorial and multigenic, and genetics may play a role in its pathogenesis $(5,6)$. The surfactant protein genes have

Correspondence: P.P.R. Lyra, Rua Socrates Guanaes Gomes, 84/401, 40296-720 Salvador, BA, Brasil. Fax: +55-71-3351-0565.

E-mail: priscilalyra@yahoo.com

Received June 9, 2010. Accepted November 26, 2010. Available online December 24, 2010. Published January 17, 2011. 
been used as candidate genes in the study of the genetics of RDS. The presence of polymorphisms and mutations in the protein $B$ gene has been implicated in RDS (6-8).

SP-B is a hydrophobic protein secreted by type II cells in the lung and is essential for normal pulmonary function $(9,10)$. It is required for synthesis of lamellar bodies and for the reduction of surface tension at the air-liquid interface. SP-B is necessary for the formation of the lungs and of tubular myelin, as well as for the processing of SP-C. The absence of SP-B in animals and humans results in respiratory failure and death shortly after birth (11-15).

Several studies have evaluated the association of SP-A and SP-B gene polymorphisms with RDS (16-21), but the functional consequences of the allelic variations of the SP genes are not well understood, and clarification of genetic diversity is a challenge for the future (6).

The study of the polymorphisms/mutations of surfactant proteins can help to understand individual variability in the susceptibility to pulmonary diseases. These genetic variants can be valuable markers in the mapping of several pathologies, particularly RDS. The objectives of the present study are to determine the frequencies of four SP-B gene polymorphisms (A/C at nucleotide $-18, \mathrm{C} / \mathrm{T}$ at nucleotide $1580, A / G$ at nucleotide 9306 , and $\mathrm{G} / \mathrm{C}$ at nucleotide 8714 ) in Brazilian preterm babies with and without RDS, to compare the polymorphism frequencies between the two groups and to evaluate differences related to gender, race and RDS.

\section{Material and Methods}

\section{Study population}

This was a case-control study in which the samples and information were prospectively collected. We studied 151 neonates classified into two groups, preterm newborns without RDS and preterm newborns with RDS. The first group consisted of 79 preterm newborns with no respiratory distress; 42 (53\%) were girls and 37 (47\%) were boys, 34 (43\%) were black, 16 (20\%) were white, and 29 (37\%) were non-black/non-white. Weight ranged from 1170 to $3260 \mathrm{~g}$ (mean: $1828 \mathrm{~g}$ ), and gestational age ranged from 29 to 35 weeks and 6 days (mean: 33.9 weeks).

The RDS group consisted of 72 preterm neonates; 31 (43\%) were girls and $41(57 \%)$ were boys, $32(44 \%)$ were black, 9 (13\%) were white, and 31 (43\%) were non-black/ non-white. Weight ranged from 614 to $2410 \mathrm{~g}$ (mean: 1518 g) and mean gestational age was 32 weeks (range: 26 to 35 weeks; Table 1).

The data of the newborns and their mothers were collected at the same time when informed written consent was obtained.

Patients were classified according to ethnicity, gestational age, and gender. Ethnicity was based on the parents' characteristics (shape of nose, mouth, skin color, kind of hair). Premature newborns were divided into three groups according to gestational age: newborns aged 26 to 30 weeks, 31 to 33 weeks and 6 days, and 34 to 35 weeks and 6 days.

The study protocol was approved by the Ethics Committees of the following participating centers: Maternidade Climério de Oliveira, Universidade Federal da Bahia, and Maternidade Prof. José Maria de Magalhães Neto, Salvador, BA, Brazil, from February 2009 to April 2010.

\section{Inclusion criteria}

The newborns were divided into two groups: preterm newborns without RDS = gestational age between 26 and 35 weeks and 6 days; RDS group = preterm newborns with RDS and gestational age between 26 and 35 weeks and 6 days. The diagnosis of RDS was based on the following clinical and radiological criteria: signs and symptoms of respiratory distress (grunting, intercostal retraction, nasal flaring, cyanosis and tachypnea), chest radiographs with a diffuse reticulogranular pattern, and air bronchograms.

\section{Exclusion criteria}

Preterm newborns with other diseases, genetic syndromes, congenital malformations, and other associated pathologies were excluded.

\section{Laboratory tests}

Blood sample collection. Blood collection was performed at the hospital at the same time as other routine exams. Blood samples were placed in tubes containing EDTA and kept at $4^{\circ} \mathrm{C}$ until DNA extraction.

DNA extraction and PCR amplification. The genomic DNA of the newborns was purified from total blood using the Wizard Genomic DNA Purification Kit ${ }^{\circledR}$ (Promega, USA)

Table 1. Clinical features of preterm newborns with and without respiratory distress syndrome (RDS).

\begin{tabular}{lcc}
\hline Clinical features & $\begin{array}{c}\text { Without RDS } \\
(\mathrm{N}=79)\end{array}$ & $\begin{array}{c}\text { With RDS } \\
(\mathrm{N}=72)\end{array}$ \\
\hline Gender, $\mathrm{N}(\%)$ & & \\
Female & $42(53)$ & $31(43)$ \\
Male & $37(47)$ & $41(57)$ \\
Race, $\mathrm{N}(\%)$ & & \\
Black & $34(43)$ & $32(44)$ \\
White & $16(20)$ & $9(13)$ \\
Non-black/non-white & $29(37)$ & $31(43)$ \\
Weight (g) - mean & 1828 & 1518 \\
$\quad$ Minimum & 1170 & 614 \\
$\quad$ Maximum & 3260 & 2410 \\
Gestational age ${ }^{*}$ (mean) & 33.9 & 32 \\
Minimum & 29.0 & 26 \\
Maximum & 35.9 & 35 \\
\hline
\end{tabular}

*Gestational age was determined by the Ballard method (22). 
according to manufacturer instructions. DNA from patient and healthy newborn blood samples was amplified by PCR amplification protocols, as described by Lin et al. (23).

A DNA sequence of 10,751 spanning all SP-B genes, including the 5' and 3' flanking regions, was amplified using the Expand Long Template PCR system (Roche, Germany). The primers used were specific for SP-B, sense primer 536 and antisense primer 535. The PCR mixture (total volume of $50 \mu \mathrm{L}$ ) consisted of $100 \mathrm{ng} / \mu \mathrm{L}$ DNA, 1X PCR buffer, $2.0 \mathrm{mM} \mathrm{MgCl}_{2}, 1.5 \mathrm{mM}$ deoxyribonucleotide triphosphates (dNTPs) (Promega ${ }^{\circledR}$ ), 150 ng sense primer 536 and anti-sense primer 535 , and $0.75 \mu \mathrm{L}$ of the Expand enzyme. PCR cycles consisted of one cycle at $95^{\circ} \mathrm{C}$ for 2 min, followed by 10 cycles at $95^{\circ} \mathrm{C}$ for $30 \mathrm{~s}, 58^{\circ} \mathrm{C}$ for $1 \mathrm{~min}$ and $72^{\circ} \mathrm{C}$ for $10 \mathrm{~min}$ and then by 20 cycles at $95^{\circ} \mathrm{C}$ for 30 $\mathrm{s}, 62^{\circ} \mathrm{C}$ for $10 \mathrm{~min}$ and $68^{\circ} \mathrm{C}$ for $12 \mathrm{~min}$, with a final 20 -min extension $\left(68^{\circ} \mathrm{C}\right)$.

For amplification of the segments that span the polymorphisms mentioned previously, we used previously described primers and protocols $(23,24)$. All primers used are listed in Table 2.

The PCR product obtained in the first PCR assay was used as a substrate for amplification of fragments with polymorphic sites (Table 3). The PCR mixture (total volume 30 $\mu \mathrm{L})$ consisted of $1 \mu \mathrm{L}$ of the $11-\mathrm{kb}$ PCR products, $0.2 \mu \mathrm{M}$ of each primer, 0.15 mM dNTPs, 1X PCR buffer, and $0.15 \mu \mathrm{L}$ AmpTaq (Roche). The cycles consisted of $95^{\circ} \mathrm{C}$ for 2 min followed by 5 cycles of $95^{\circ} \mathrm{C}$ for $30 \mathrm{~s}, 50^{\circ} \mathrm{C}$ for $1 \mathrm{~min}$, and $70^{\circ} \mathrm{C}$ for $1 \mathrm{~min}$ and 30 cycles of $95^{\circ} \mathrm{C}$ for $30 \mathrm{~s}$, $55^{\circ} \mathrm{C}$ for $1 \mathrm{~min}$, and $70^{\circ} \mathrm{C}$ for $1 \mathrm{~min}$. The final extension was at $72^{\circ} \mathrm{C}$ for $2 \mathrm{~min}$.

\section{Genotyping of SP-B polymorphisms \\ We analyzed the following four SP-B polymorphisms: $\mathrm{A} / \mathrm{C}$ at nucleotide -18 , $\mathrm{C} / \mathrm{T}$ at nucleotide $1580, \mathrm{~A} / \mathrm{G}$ at nucleotide 9306, and G/C at 8714 . The genotypes} Refs. 23 and 24. were defined based on the analysis of the PCR products obtained from the restriction enzyme reactions [PCRbased converted restriction fragment length polymorphism (cRFLP)], as described by Lin et al. $(23,24)$. Six microliters of the second PCR product was subjected to digestion with the restriction enzymes Apall, Hinfl, Ddel, and Bfal according to manufacturer specifications. The digested products were identified on 8 or $10 \%$ polyacrylamide gel.

\section{Statistical analysis}

Descriptive statistics were used to describe the categorical and numerical variables of the newborns' characteristics. Frequency distribution for categorical variables, central trend measures and variability measures for numerical variables were also used.

The Fisher exact test was applied to polymorphism frequency data. Logistic regression analyses and the odds ratio were calculated to detect the contribution of the studied variables (multivariable estimative for the linear coefficients) to the development of RDS. The confidence interval was set at $95 \%$.

In the logistic model for gestational age, the reference

Table 2. Primers used in the study.

\begin{tabular}{lll}
\hline Primers & Direction & Sequence $5^{\prime} \Rightarrow 3^{\prime}$ \\
\hline 535 & Anti-sense & GCGACTAGTCTATGACGTCTGCTTCTCTGCCAAGGGAGT \\
536 & Sense & GCGGTCGACTCATCATGGTACTAATTTGCCCGTCCA \\
556 & Sense & GTCCAGCTATAAGGGGCCGTG \\
$95 A$ & Anti-sense & GTGAGTGGTGAGCTGCCTA \\
133 & Sense & CTCGAATTCACTCGTAACTCCAGCACCC \\
584 & Anti-sense & GTGAGCTTGCAGCCCTCTCA \\
101 & Sense & CTCGAATTCAGGACATACACACAGTCCCT \\
102 & Anti-sense & CCAGCTGAGCTTTCAGCAGA \\
557 & Sense & CTGTGTAATACAATGTCTGCACTA \\
121 & Anti-sense & CTCGAATTCTGCTGGATTGCAGGTGTGA \\
\hline
\end{tabular}

Nucleotide positions are according to Ref. 25. The sequences of the primers are from

Table 3. Location of polymorphism sites of the SP-B gene.

\begin{tabular}{|c|c|c|c|c|c|c|}
\hline \multirow[t]{2}{*}{ Polymorphism } & \multirow[t]{2}{*}{ Gene location } & \multicolumn{2}{|c|}{ Nucleotide } & \multirow[t]{2}{*}{ Primers } & \multirow[t]{2}{*}{ PCR fragment size } & \multirow[t]{2}{*}{ Restriction enzyme } \\
\hline & & Position & Change & & & \\
\hline $\mathrm{A} / \mathrm{C}-18$ & 5' flanking & 18 & $\mathrm{~A} / \mathrm{C}$ & $556 / 95 A$ & $167 \mathrm{bp}$ & Apall \\
\hline C/T 1580 & Exon 4 & 1580 & $\mathrm{C} / \mathrm{T}$ & $133 / 584$ & $270 \mathrm{bp}$ & Ddel \\
\hline A/G 9306 & 3'UTR & 9306 & $\mathrm{~A} / \mathrm{G}$ & $557 / 121$ & $129 \mathrm{bp}$ & Bfal \\
\hline G/C 8714 & 3'UTR & 8714 & $\mathrm{G} / \mathrm{C}$ & $101 / 102$ & $784 \mathrm{bp}$ & Hinfl \\
\hline
\end{tabular}

Nucleotide positions are according to Ref. 25. The sequences of the primers have been described in Refs. 23 and 24 and are given in Table 2. 
category was 26 to 30 weeks and 6 days; for the gender variable, female; for race, black; for the G/C 8714 polymorphism, the GG genotype; for the $\mathrm{C} / \mathrm{T} 1580$ polymorphism, the CC genotype, and for the A/G 9306 and A/C -18 polymorphisms, the AA genotype.

\section{Results}

Twenty (27\%) mothers in the group without RDS had premature rupture of membranes, 27 $(36 \%)$ had gestational hypertension, $6(8 \%)$ had chronic hypertension, 2 (3\%) had diabetes mellitus, $15(21 \%)$ had urinary tract infection, and 4 $(5 \%)$ had other diseases. Among the mothers of the RDS group, 17 (25\%) had premature rupture of membranes, $19(28 \%)$ had gestational hypertension, $16(24 \%)$ had chronic hypertension, $2(3 \%)$ had diabetes mellitus, $9(13 \%)$ had urinary tract infection, and $5(7 \%)$ had other medical conditions. Thirty-eight (48\%) mothers in the control group and 41 (57\%) mothers in the RDS group used antenatal steroids.

\section{Polymorphism analysis}

Analysis of $A / G 9306$ polymorphism using the logistic regression model showed that gestational age was the most important factor for occurrence of the disease and the $A G$ genotype was a protective factor against $\operatorname{RDS}(\mathrm{OR}=0.1681$; $95 \% \mathrm{Cl}=0.0426-0.6629$; Tables 4 and 5). Figure 1 shows the frequencies of the polymorphisms in each group.

The analysis of the G/C 8714, C/T 1580, and A/C -18
Table 4. Logistic regression analysis of the A/G 9306 polymorphism.

\begin{tabular}{lrcrl}
\hline Coefficients & Estimate & Standard error & z-value & "Pr $(>|z|) ”$ \\
\hline (“Intercept”) & 2.0808 & 0.8836 & 2.355 & 0.018532 \\
GA 31-33.9 weeks & -1.5708 & 0.8770 & -1.791 & 0.07328 \\
GA 34-35.9 weeks & -3.6319 & 0.9453 & -3.842 & 0.00012 \\
Gender - male & 0.5259 & 0.4681 & 1.123 & 0.26129 \\
Race - white & -0.5539 & 0.6474 & -0.856 & 0.392261 \\
Race - NW/NB & -0.1016 & 0.5117 & -0.199 & 0.842556 \\
A/G & -1.7833 & 0.7001 & -2.547 & 0.010858 \\
G/G & -0.8687 & 0.7869 & -1.104 & 0.269633 \\
\hline
\end{tabular}

$\mathrm{GA}=$ gestational age $; \mathrm{NW} / \mathrm{NB}=$ non-white/non-black .

Table 5. Odds ratio of the A/G 9306 polymorphism.

\begin{tabular}{lcccc}
\hline & OR & IL 95\%Cl & SL 95\%Cl & P \\
\hline GA 31-33.9 weeks & 0.2079 & 0.0373 & 1.1596 & \\
GA 34-35.9 weeks & 0.0265 & 0.0041 & 0.1688 & 0.0001 \\
Gender - male & 1.6919 & 0.6759 & 4.2350 & \\
Race - white & 0.5747 & 0.1616 & 2.0442 & \\
Race - NW/NB & 0.9034 & 0.3313 & 2.4629 & \\
A/G & 0.1681 & 0.0426 & 0.6629 & \\
G/G & 0.4195 & 0.0897 & 1.9614 & \\
\hline
\end{tabular}

OR = odds ratio; IL 95\% CI = inferior limit confidence interval; SL $95 \% \mathrm{Cl}=$ superior limit confidence interval; $\mathrm{GA}=$ gestational age; NW/NB = non-white/non-black.

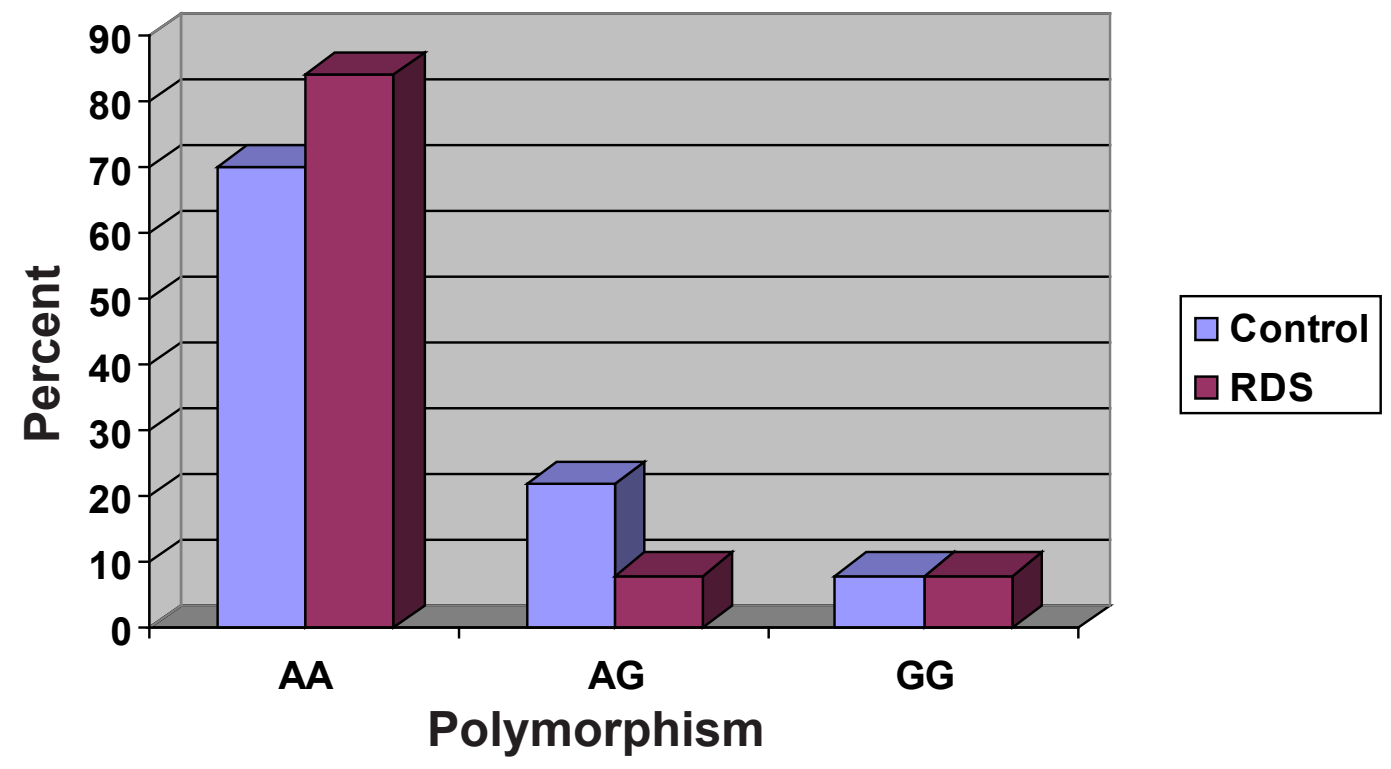

Figure 1. Frequencies of the A/G 9306 SP-B genotypes. Comparison between the respiratory distress syndrome (RDS) group (preterm newborns with RDS) and the control group (preterm newborns without RDS). 
polymorphisms demonstrated no association between the genotypes from these polymorphic sites and RDS, gender or race.

\section{Discussion}

RDS is caused by primary surfactant deficiency and is the most frequent form of respiratory insufficiency in the preterm newborn. Despite advances in treatments with antenatal steroids, exogenous surfactant and mechanical ventilation, this disease is still a major cause of morbidity in this group of patients $(4,26,27)$. Pulmonary morbidity has been attributed to oxygen toxicity, barotrauma, lung immaturity, and nutritional deficiencies. However, significant variations in pulmonary outcomes of similar infants with comparable exposures to oxygen, mechanical ventilation and nutritional deficiencies suggest that genetic factors also contribute to pulmonary outcomes (28). RDS is the result of complex interactions between several environmental and genetic factors associated with prematurity, gender, race, and maternal diseases (6). Some genetic variants of surfactant proteins, particularly SP-A and SP-B, are risk or protective factors in RDS etiology $(13,16,17,29)$.

The present study determined the frequency of four SP-B polymorphisms (G/C at nucleotide $8714, \mathrm{C} / \mathrm{T}$ at nucleotide 1580, A/G at nucleotide 9306, and A/C at nucleotide -18) in 79 preterm babies without RDS and 72 preterm babies with RDS in a Brazilian population of the city of Salvador, Bahia, and the association of these polymorphisms with gender and race.

The results of our study showed that gestational age was the most important factor for the occurrence of RDS in the AG 9306 polymorphism (Tables 4 and 5) and also in the other three polymorphisms (data not shown).

The incidence of RDS increases with decreasing gestational age, with about $25 \%$ of babies affected at 34 weeks of gestation and up to $80 \%$ of babies affected at less than 28 weeks (4). This can be explained by the fact that premature babies are unable to produce appropriate amounts of surfactant and by the structural immaturity of the lungs at lower ages (1).

The G/C 8714 polymorphism is located in the 3'UTR of the SP-B gene, corresponding to the flanking region. Although it is located outside the protein translation site, this region can somehow impact gene expression and/or protein function (24).

In our study, there was no statistically significant difference in the distribution of the genotypes of the G/C polymorphism at nucleotide 8714 in patients with and without RDS. In 2007, we studied the same four polymorphisms in a group of 100 healthy term babies and a group of 50 preterm babies with RDS (30). When race was analyzed separately, among the white individuals, the GG genotype was only found in the RDS group. These findings suggested that the GG genotype might be a risk factor for RDS, and the GC genotype might be a protective factor. In a study of patients with alveolar proteinosis, Lin et al. (24) analyzed a family in whom 14 newborns died due to early respiratory insufficiency. The G/C polymorphism at nucleotide 8714 did not have a pathophysiological impact in this population. Therefore, our results should be analyzed with caution. They reinforce the need for other studies in the Brazilian population to define the real role of this genotype in RDS.

The $\mathrm{C} / \mathrm{T}$ polymorphism at nucleotide 1580 is located at the end of exon 4 at nucleotide 1580 and can alter the translation of amino acid 131 by substitution of threonine (AㄷT) with isoleucine (ATT) (23). This change eliminates a potential $\mathrm{N}$-linked glycosylation site but the real consequences of this alteration are not known $(7,31)$. In the literature, most studies suggest that the C/C genotype might be associated with a greater risk of developing RDS and other pulmonary diseases. In our study, we did not find any statistically significant difference in the frequencies of genotypes CC, CT, and TT when the healthy term group and the RDS group were compared. Although genotype $\mathrm{CC}$ was more frequently found in the RDS group than in the control group, this difference was not statistically significant (Table 4).

The A/G polymorphism at nucleotide 9306 is located in the 3'UTR. In our study, we found that the AG genotype of the $A / G$ polymorphism was protective against RDS in the population studied $(O R=0.17)$. This result differs from $a$ study by another laboratory where the AG genotype was considered to be a risk factor for RDS (7). In our 2007 study on a population of healthy term and preterm newborns from the city of São Paulo, we did not find a protective effect of the AG genotype (30).

The different results between our studies and others might be attributed to ethnic differences or to sample size. Liu et al. (32) have reported that ethnic background is an important risk factor in analytical studies of allele and genotype frequencies. They analyzed the similarity of genetic markers among populations of three different ethnic groups (Caucasian, Black, and Hispanic), in order to observe whether individuals of different races or ethnic groups could be grouped together in linkage studies. The results showed that the allele and genotype frequencies can differ between distinct ethnic groups, especially between ethnic groups of different races (32).

The Brazilian population is one of the most heterogeneous populations in the world, originating from the miscegenation of Indians, blacks and whites. The distribution of these three different ethnic groups in the territory did not occur in a homogeneous way. In the city of Salvador, in particular, there is a higher prevalence of individuals of African descent, as well as miscegenation of individuals of other backgrounds.

The analysis of the interaction between SP-A and SP-B might be useful for the evaluation of risk to develop RDS in patients with the A/G 9306 genotype (7). Since our study 
did not evaluate SP-A polymorphisms, we were unable to analyze the SP-A and SP-B interaction. Recently, Wambach et al. (33) also suggested that reduced SP-C transcription contributes to the genetic risk for neonatal RDS in developmentally susceptible infants.

The A/C -18 polymorphism is located in the 5'UTR and may impact the initiation of mRNA transcription. In the case-control study of Floros et al. (18), the association of SP-A and SP-B polymorphisms was evaluated in white and African-American newborns with RDS. The authors found a higher frequency of the AA genotype of the $A / C$ -18 polymorphism in African-American neonates. This

\section{References}

1. Avery ME, Mead J. Surface properties in relation to atelectasis and hyaline membrane disease. AMA J Dis Child 1959; 97: $517-523$

2. Goerke J. Pulmonary surfactant: functions and molecular composition. Biochim Biophys Acta 1998; 1408: 79-89.

3. Haagsman HP, Diemel RV. Surfactant-associated proteins: functions and structural variation. Comp Biochem Physiol A Mol Integr Physiol 2001; 129: 91-108.

4. Sweet DG, Halliday HL. The use of surfactants in 2009. Arch Dis Child Educ Pract Ed 2009; 94: 78-83.

5. Floros J, Kala P. Surfactant proteins: molecular genetics of neonatal pulmonary diseases. Annu Rev Physiol 1998; 60: 365-384.

6. Haataja R, Hallman M. Surfactant proteins as genetic determinants of multifactorial pulmonary diseases. Ann Med 2002; 34: 324-333.

7. Floros J, Fan R, Diangelo S, Guo X, Wert J, Luo J. Surfactant protein (SP) B associations and interactions with SP-A in white and black subjects with respiratory distress syndrome. Pediatr Int 2001; 43: 567-576.

8. Hanvas A, Cole FS, Nogee LM. Genetic disorders of surfactant proteins. Neonatology 2007; 91: 311-317.

9. Longo ML, Bisagno AM, Zasadzinski JA, Bruni R, Waring AJ. A function of lung surfactant protein SP-B. Science 1993; 261: 453-456.

10. Floros J, Phelps DS. Pulmonary surfactant. In: Biebuyck JF, Lynch C, Maze M, Saidamn Lj, Yaksh TL, Zapol WM (Editors), Anesthesia: biologic foundations. Lippincott-Raven, New York; 1997: 1257-1279.

11. Nogee LM, de Mello DE, Dehner LP, Colten HR. Brief report: deficiency of pulmonary surfactant protein $B$ in congenital alveolar proteinosis. N Engl J Med 1993; 328: 406-410.

12. Nogee LM. Surfactant protein-B deficiency. Chest 1997; 111: 129S-135S.

13. Nogee LM, Wert SE, Proffit SA, Hull WM, Whitsett JA. Allelic heterogeneity in hereditary surfactant protein B (SP-B) deficiency. Am J Respir Crit Care Med 2000; 161: 973-981.

14. Clark JC, Wert SE, Bachurski CJ, Stahlman MT, Stripp BR, Weaver TE, et al. Targeted disruption of the surfactant protein B gene disrupts surfactant homeostasis, causing respiratory failure in newborn mice. Proc Natl Acad Sci U S A 1995; 92: 7794-7798.

15. Tokieda K, Whitsett JA, Clark JC, Weaver TE, Ikeda K, Mc- observation was made in preterm newborns with RDS and gestational age between 28 and 31 weeks (7). In our study, we found that the AA genotype was high in the RDS population but not significantly so. We could not detect a statistically significant difference in the distribution of the genotypes of the $\mathrm{A} / \mathrm{C}-18$ polymorphism between healthy term newborns and the RDS groups.

The present study demonstrated that the AG genotype of the AG 9306 polymorphism was a protective factor against the development of RDS. The other polymorphisms studied (G/C at $8714, \mathrm{C} / \mathrm{T}$ at $1580, \mathrm{~A} / \mathrm{C}$ at -18$)$ were not associated with RDS.
Connell KB, et al. Pulmonary dysfunction in neonatal SP-Bdeficient mice. Am J Physiol 1997; 273: L875-L882.

16. Floros J, Veletza SV, Kotikalapudi P, Krizkova L, Karinch AM, Friedman C, et al. Dinucleotide repeats in the human surfactant protein-B gene and respiratory-distress syndrome. Biochem J 1995; 305 (Part 2): 583-590.

17. Kala P, Ten HT, Nielsen H, Dunn M, Floros J. Association of pulmonary surfactant protein A (SP-A) gene and respiratory distress syndrome: interaction with SP-B. Pediatr Res 1998; 43: 169-177.

18. Floros J, Fan R, Matthews A, Diangelo S, Luo J, Nielsen H, et al. Family-based transmission disequilibrium test (TDT) and case-control association studies reveal surfactant protein A (SP-A) susceptibility alleles for respiratory distress syndrome (RDS) and possible race differences. Clin Genet 2001; 60: 178-187.

19. Ramet M, Haataja R, Marttila R, Floros J, Hallman M. Association between the surfactant protein A(SP-A) gene locus and respiratory-distress syndrome in the Finnish population. Am J Hum Genet 2000; 66: 1569-1579.

20. Haataja R, Ramet M, Marttila R, Hallman M. Surfactant proteins $A$ and $B$ as interactive genetic determinants of neonatal respiratory distress syndrome. Hum Mol Genet 2000; 9: 2751-2760.

21. Haataja R, Marttila R, Uimari P, Lofgren J, Ramet M, Hallman M. Respiratory distress syndrome: evaluation of genetic susceptibility and protection by transmission disequilibrium test. Hum Genet 2001; 109: 351-355.

22. Ballard JL, Khoury JC, Wedig K, Wang L, Eilers-Walsman BL, Lipp R. New Ballard Score, expanded to include extremely premature infants. J Pediatr 1991; 119: 417-423.

23. Lin Z, deMello DE, Wallot M, Floros J. An SP-B gene mutation responsible for SP-B deficiency in fatal congenital alveolar proteinosis: evidence for a mutation hotspot in exon 4. Mol Genet Metab 1998; 64: 25-35.

24. Lin Z, deMello DE, Batanian JR, Khammash HM, Diangelo $\mathrm{S}$, Luo J, et al. Aberrant SP-B mRNA in lung tissue of patients with congenital alveolar proteinosis (CAP). Clin Genet 2000; 57: 359-369.

25. Pilot-Matias TJ, Kister SE, Fox JL, Kropp K, Glasser SW, Whitsett JA. Structure and organization of the gene encoding human pulmonary surfactant proteolipid SP-B. DNA 1989; 8: 75-86. 
26. Curstedt T, Johansson J. New synthetic surfactants - basic science. Biol Neonate 2005; 87: 332-337.

27. Jobe AH. Pulmonary surfactant therapy. N Engl J Med 1993; 328: 861-868.

28. Cole FS, Hamvas A, Nogee LM. Genetic disorders of neonatal respiratory function. Pediatr Res 2001; 50: 157-162.

29. Veletza SV, Rogan PK, TenHave T, Olowe SA, Floros J. Racial differences in allelic distribution at the human pulmonary surfactant protein B gene locus (SP-B). Exp Lung Res 1996; 22: 489-494.

30. Lyra PP, Vaz FA, Moreira PE, Hoffmann JW, deMello DE, Diniz EM. Comparison of surfactant protein $B$ polymorphisms of healthy term newborns with preterm newborns having respiratory distress syndrome. Braz J Med Biol Res 2007;
40: 779-786.

31. Wang G, Christensen ND, Wigdahl B, Guttentag SH, Floros $\mathrm{J}$. Differences in $\mathrm{N}$-linked glycosylation between human surfactant protein-B variants of the $\mathrm{C}$ or $\mathrm{T}$ allele at the singlenucleotide polymorphism at position 1580: implications for disease. Biochem J 2003; 369: 179-184.

32. Liu W, Bentley CM, Floros J. Study of human SP-A, SP-B and SP-D loci: allele frequencies, linkage disequilibrium and heterozygosity in different races and ethnic groups. BMC Genet 2003; 4: 13.

33. Wambach JA, Yang P, Wegner DJ, An P, Hackett BP, Cole $F S$, et al. Surfactant protein-C promoter variants associated with neonatal respiratory distress syndrome reduce transcription. Pediatr Res 2010; 68: 216-220. 